\title{
MATRICIALIDADE SOCIOFAMILIAR: COMPROMISSO DA POLÍTICA DE ASSISTÊNCIA SOCIAL E DIREITO DA FAMÍLIA ${ }^{1}$
}

\author{
Dalva Azevedo Gueiros ${ }^{2}$ \\ Thais Felipe Silva dos Santos ${ }^{3}$
}

\section{RESUMO}

Este artigo busca refletir sobre matricialidade sociofamiliar em termos conceituais e em sua operacionalidade em espaços referenciais de assistência social, situando-se na articulação entre os fundamentos teórico-metodológicos advindos do Serviço Social e a prática profissional. Discute as famílias contemporâneas e suas questões, sobretudo aquelas que dependem da atenção do Estado para promover o cuidado e a proteção a seus membros. Nesse sentido, parte-se do entendimento de que a situação presente de famílias socialmente vulnerabilizadas é fruto de percursos sociais complexos, resultantes da desigualdade social e de transformações no mundo do trabalho e nas relações de gênero, entre outros aspectos. A partir de informações empíricas coletadas entre assistentes sociais, adentra-se à análise de aspectos que norteiam a intervenção profissional em Centros de Referência de Assistência Social, e toma-se como pressuposto que uma proteção social efetiva requer o acesso de todos a direitos sociais.

PALAVRAS-CHAVE: Assistência Social, Famílias, Matricialidade Sociofamiliar, Serviço Social

\footnotetext{
${ }^{1}$ Para elaboração do presente artigo utilizou-se também resultados de pesquisa que, originalmente, embasaram o Trabalho de Conclusão do Curso de Serviço Social (UNICSUL - São Paulo/SP), de Thais Felipe Silva dos Santos, orientado por Dalva Azevedo Gueiros, intitulado "O trabalho com famílias nos CRAS e CREAS de São Paulo: a matricialidade sociofamiliar tem centralidade?”.

${ }^{2}$ Mestre e doutora em Serviço Social; especialista em Família; assistente social no Tribunal de Justiça do Estado de São Paulo; professora na Graduação em Serviço Social e no Mestrado em Políticas Sociais da Universidade Cruzeiro do Sul; co-coordenadora do Núcleo de Estudos e Pesquisas sobre Políticas e Práticas Sociais com Famílias do Mestrado em Políticas Sociais da Universidade Cruzeiro do Sul; pesquisadora associado do Núcleo de Estudos sobre a Criança e o Adolescente - NECA. E-mail: dalazg@uol.com.br.

${ }^{3}$ Graduada em Serviço Social pela Universidade Cruzeiro do Sul; assistente social da Irmandade Santa Casa de Misericórdia de São Paulo. E-mail: thaislipe@gmail.com.
} 


\section{INTRODUÇÃO}

A Política Nacional de Assistência Social (PNAS) ${ }^{4}$, cuja proposta é efetivar a assistência social como política pública de Estado, materializa os pressupostos da Constituição Federal de 1988 no que se refere a um dos eixos da Seguridade Social - o da Assistência Social ${ }^{5}$-, com o escopo de estruturar, por meio do Sistema Único de Assistência Social (SUAS) ${ }^{6}$, a cidadania como condição humana fundamental.

A PNAS, que tem por objetivo a proteção social básica e especial a indivíduos, famílias e grupos que dela necessitam, visa constituir-se como referência universal no âmbito socioassistencial e é entendida na perspectiva de política afiançadora de direitos sociais não contributivos. Nesse sentido, é um compromisso do Estado com a cidadania, ampliando a agenda de resposta do ente federativo pelo reconhecimento dos direitos humanos e sociais, afinal é das mãos dos trabalhadores que sai a mais-valia que gera a opulência.

Essa premissa leva ao entendimento de que há uma dívida pública com o trabalhador, já que a riqueza produzida não é dividida de forma justa com a sociedade que a produz, cabendo a ele uma ínfima parte do que é produzido. “É sabido e notório que a pobreza resulta do modelo de acumulação adotado pela sociedade de mercado e, no caso brasileiro, pela imensa desigualdade e dívida social que marca a história do modelo econômico brasileiro” (SPOSATI, 2009, p. 5-6).

Assumir essa perspectiva analítica e, a partir dela, alicerçar seu cotidiano de trabalho é o desafio maior de um profissional compromissado com a justiça social. Para os assistentes sociais que estão na gestão e/ou execução da política de assistência social

\footnotetext{
${ }^{4}$ Resolução n ${ }^{\circ}$ 145, de 15 de outubro de 2004, do Conselho Nacional de Assistência Social - CNAS.

${ }^{5}$ Regulamentado pela Lei Orgânica da Assistência Social, Lei no 8.742, de 7 de dezembro de 1993.

${ }^{6}$ A Norma Operacional Básica da Assistência Social (NOB/SUAS) foi aprovada pelo Conselho Nacional de Assistência Social em 15 de julho de 2005 (Resolução nº 130) e em 06 de julho de 2011 foi sancionada a lei $n^{\circ} 12.435$, que passou a regulamentar o SUAS.
} 
e que primam pela defesa dos direitos sociais, certamente não são simples as mediações entre a população, com suas demandas, e a resposta estatal, por meio das políticas sociais.

Situando nossas reflexões na articulação entre os fundamentos teóricometodológicos e a prática profissional, nosso objetivo neste artigo é desvelar o conceito de matricialidade sociofamiliar e, a partir daí, analisar a efetividade desse pressuposto na intervenção do assistente social junto às famílias usuárias da política de assistência social, visando agregar conhecimento às profissões compromissadas em contribuir para a promoção da cidadania e em levar a efeito os pressupostos da PNAS.

\section{A PNAS E SUA DIRETRIZ RELATIVA À FAMÍLIA}

A PNAS almeja levar a inclusão social aos usuários e, nesse sentido, estabelece as formas de proteção básica e especial que regem a assistência social brasileira e institui princípios, diretrizes e objetivos com vistas a uma proteção social que garanta "segurança de sobrevivência (de rendimentos e de autonomia); de acolhida; de convívio ou vivência familiar” (PNAS, 2004, p. 31). Concebendo a assistência social como dever do Estado, fixa como diretrizes:

I - Descentralização político-administrativa, cabendo a coordenação e as normas gerais à esfera federal e a coordenação e execução dos respectivos programas às esferas estadual e municipal, bem como a entidades beneficentes e de assistência social, garantindo o comando único das ações em cada esfera de governo, respeitando-se as diferenças e as características socioterritoriais locais;

II - Participação da população, por meio de organizações representativas, na formulação das políticas e no controle das ações em todos os níveis; 
III - Primazia da responsabilidade do Estado na condução da Política de Assistência Social em cada esfera de governo;

IV - Centralidade na família para concepção e implementação dos benefícios, serviços, programas e projetos (PNAS, 2004, p. 32-3).

A qualificação da família como principal agente da socialização primária ${ }^{7}$ e de locus privilegiado para o desenvolvimento da cidadania, da proteção e do cuidado de seus membros certamente foi determinante para sua primazia na concepção e implementação da política de assistência social, posto que, para assumir esse papel que lhe é socialmente atribuído, faz-se necessário que ela seja alvo de atenção pelo Estado.

Todavia, para além da centralidade da família, a PNAS estabelece a matricialidade sociofamiliar, colocando em foco as necessidades e peculiaridades das famílias, entendendo-as como sujeito coletivo, conforme referencia Sposati (2009). Conjecturamos que pensar a matricialidade sociofamiliar significa compreender o momento e a situação social da família, com a perspectiva de gerir tais aspectos a partir de suas especificidades.

Nesse sentido, a PNAS reconhece que o enfrentamento da questão social passa pelo mundo da família, assegurados o direito à convivência familiar e aos mínimos sociais que, segundo Sposati (1997), constituem padrões básicos de inclusão e garantem

[...] sobrevivência biológica, isto é, o limite de subsistência no limiar da pobreza absoluta; condições de poder trabalhar, isto é, algumas condições para poder ser empregado e poder manter-se; qualidade de vida, isto é, o conjunto de acesso a um padrão de vida por meio de serviços e garantias; desenvolvimento humano,

\footnotetext{
${ }^{7}$ Em linhas gerais, a socialização primária é o processo pelo qual se efetiva na família a transmissão de valores e o desenvolvimento de uma identidade social, com a perspectiva de preparar seus membros para o convívio em seu meio social imediato e para responder, posteriormente, às demandas que lhes são impostas na condição de adultos.
} 
isto é, a possibilidade de desenvolver as capacidades humanas, o que coloca em evidência o padrão educacional adotado em uma sociedade e a universalização do acesso a todos; [e] necessidades humanas, isto é, atender não só as necessidades gerais, mas incluir as necessidades especiais, garantindo tanto a igualdade como a equidade (SPOSATI, 1997, p. 15-6).

Para alicerçar a família nessa perspectiva de lhe assegurar os mínimos sociais, é importante compreendê-la como unidade relacional, cuja situação no tempo presente é fruto de processos históricos complexos, resultantes da desigualdade social, de transformações ocorridas no mundo do trabalho e nas relações de gênero e do fortalecimento da lógica individualista, entre outros aspectos.

Frente às premissas constantes no texto desse marco regulatório relativo à assistência social e considerando que a família não é homogênea, ao contrário, é plural e contempla contradições advindas da singularidade de seus membros e de sua relação com a sociedade, é importante discutir as premissas que orientam a formulação e a implementação do trabalho social com famílias, notadamente a matricialidade sociofamiliar, em CRAS $^{8}$ e CREAS ${ }^{9}$. Emerge daí uma das primeiras indagações: como o Serviço Social desses espaços socioassistenciais pode intervir junto às famílias tomando por base a matricialidade sociofamiliar se, via de regra, as políticas e programas sociais são definidos a priori e em instâncias superiores.

A centralidade na família e a matricialidade sociofamiliar são preconizadas também no SUAS, sistema de gestão da política de assistência social no Brasil, no qual

${ }^{8}$ O CRAS é uma unidade pública estatal, que atua com famílias e indivíduos em seu contexto comunitário, visando a orientação e o fortalecimento do convívio sociofamiliar. (MANUAL INFORMATIVO DO SUAS, 2005, p. 10).

${ }^{9}$ O CREAS é um equipamento estatal, centro de referência da assistência social que atua com famílias e indivíduos em situação de risco social e pessoal em decorrência da violação de seus direitos e/ou rompimento dos vínculos familiares (MANUAL INFORMATIVO DO SUAS, 2005, p. 11).

Revista Serviço Social \& Saúde. UNICAMP Campinas, v. X, n. 12, Dez. 2011 
são estabelecidos padrões de atendimento, como eixos de atuação, nomenclatura dos equipamentos, qualidade dos atendimentos, indicadores de avaliação e resultados, conforme Scherer (2009).

Sabemos que as diversas políticas públicas são formuladas para abranger, de forma homogênea, grande contingente populacional, enquanto os estudos realizados sobre famílias inferem que estas são marcadas por singularidades e, por conseguinte, são heterogêneas, emergindo daí importantes desafios para a gestão e execução dos serviços e benefícios sociais. Assim, impõe-se reconhecer as pressões que os processos de exclusão socioeconômicos e culturais geram sobre as famílias, o que torna imprescindível ao assistente social aproximar-se do cotidiano delas para conhecer de perto e de dentro as implicações dos riscos sociais nesses sujeitos de direitos ${ }^{10}$.

Diante disso, outra indagação que levantamos é se os profissionais de Serviço Social têm condições de operacionalizar, nos CRAS e CREAS, os eixos fundantes da PNAS, embora conheçam e reconheçam as diretrizes que a norteiam. Essa questão emerge da constatação da ainda precária implantação dos serviços, tanto no que diz respeito às condições físicas e materiais como ao quadro de trabalhadores, que deveria ser suficiente, em termos de qualificação profissional e quantidade, para atender dignamente as demandas do cotidiano de trabalho ${ }^{11}$.

A matricialidade sociofamiliar e a centralidade na família fazem parte da agenda das políticas públicas em vigor, conforme se constata nos marcos legais alavancados pela Constituição Federal de 1988, espraiadas na Política Nacional de

\footnotetext{
${ }^{10}$ Talvez seja necessário considerar que as famílias que se encontram na linha de pobreza ou abaixo dela não vivam a condição de sujeitos de direitos, uma vez que a elas quase sempre foram negados direitos básicos, o que pode ter resultado em certa dificuldade de seus membros de se assumir como tendo direitos. É possível que, em certas situações, o poder público, por meio de suas instituições, tenha que oferecer suporte à família para que ela efetivamente se reconheça como sujeito de direitos.

${ }^{11}$ As reflexões e pontos de vista aqui expostos estão mais diretamente relacionados à implementação da política de assistência social na cidade de São Paulo.
} 
Assistência Social, no Plano Nacional de Promoção, Proteção e Defesa do Direito de Crianças e Adolescentes à Convivência Familiar e Comunitária e, mais ultimamente, na Lei Federal $n^{\circ}$ 12.010, de 03/08/09, que também trata de convivência familiar de crianças e adolescentes. Por isso, é relevante, para a atuação do profissional de Serviço Social, ampliar o olhar sobre a família, aproximando-se de sua realidade cotidiana e desvendando possibilidades e limites no embate com as expressões da questão social.

No Serviço Social, o sujeito da intervenção profissional guarda unidade indissociável com o objeto de atuação da profissão, a questão social. Lidar com as expressões da questão social materializadas na vida dos sujeitos - no caso, as famílias -, que são os demandadores dos serviços sociais, exige proximidade com a dinâmica que envolve suas vivências, para melhor apreensão da realidade que a cerca e para a efetividade de uma prática pensada.

Emerge daí a importância de o assistente social atuar com consciência e conhecimento, uma vez que tem sua prática balizada na “defesa intransigente dos direitos humanos e na recusa do arbítrio e do autoritarismo”, no "posicionamento em favor da equidade e justiça social, que assegure universalidade de acesso aos bens e serviços relativos aos programas e políticas sociais [...]”, além do “empenho na eliminação de todas as formas de preconceito, incentivando o respeito à diversidade, à participação de grupos socialmente discriminados e à discussão das diferenças”, entre outros princípios ético-políticos que norteiam o fazer profissional (CÓDIGO DE ÉTICA DO ASSISTENTE SOCIAL, 1993, p. 1). Enfim, reconhecer que as famílias são sujeitos de direitos, que merecem ter assegurada sua condição protetiva e ser respeitados em suas formas de composição e de organização, entre outros aspectos, conforme enfatiza a 
agenda do $13^{\circ}$ Congresso Brasileiro de Assistentes Sociais, é imprescindível à prática profissional do assistente social $^{12}$.

\section{DA CONCEITUAÇÃO AO CONHECIMENTO DA FAMÍLIA}

Conhecer a família significa pensá-la na inserção com seu meio social, em suas configurações contemporâneas e em suas funções, sem deixar de considerar sua historicidade. Assim, é fundamental entendê-la em seu contexto histórico-social e adentrar os vários fatores que compõem sua formação na atualidade.

A realidade cotidiana nos impõe o desafio de analisar como a composição, a forma de desempenhar os papéis que lhe são atribuídos e, principalmente, como as determinações advindas da localização em termos de classe social, gênero e etnia se expressam na organização da família, configurando fragilidades e potencialidades no enfrentamento da luta pela sobrevivência.

Refletir sobre a família é, portanto, refletir sobre uma unidade relacional plural e mutável, de suporte a seus membros e também de confronto entre eles, marcada por movimentos que denotam as transformações que ocorrem na sociedade. Nesse sentido, o casamento embasado na escolha mútua dos parceiros, a separação entre sexualidade e reprodução, as novas tecnologias reprodutivas, a presença cada vez mais forte da mulher no mercado formal de trabalho, a união entre pessoas do mesmo sexo e

\footnotetext{
${ }^{12}$ Da Agenda Política do XIII CBAS, relativa ao eixo "Família e relações sociais”, queremos destacar os seguintes tópicos: "Qualificar o trabalho social com famílias visando fortalecer a especificidade do Serviço Social em equipes multiprofissionais; ampliar o debate sobre família e relações sociais visando desconstruir a associação entre desigualdade social e configurações familiares; defender a universalidade dos direitos sociais como condição fundamental para a efetiva proteção social das famílias; combater todas as formas de preconceito e discriminação relacionadas à constituição e configuração das famílias" (Agenda Política do XIII CBAS, disponível em: http://www.cfess.org.br/arquivos/Agenda_XIII_CBAS.pdf. Acessado em 19/03/2011.
} 
a adoção de crianças por esses casais, além dos constantes rompimentos de laços conjugais, resultaram em novas formas de ser família.

Diante dessa complexidade, definir, mesmo que precariamente, essa que continua sendo vista como a primeira e mais importante referência social do indivíduo tem merecido dos estudiosos certo cuidado. De um lado, é necessário diferenciá-la de outros agrupamentos humanos e, de outro, é importante não restringi-la ao parentesco e à coabitação.

Para Sarti (2005), a família é um grupo social que concretiza vínculos de parentesco (de consanguinidade entre irmãos, de descendência entre pai e filho e mãe e filho, e de afinidade, por meio do casamento). Acrescente-se a isso o compartilhamento de um mesmo cotidiano, da união por afeto e com objetivos de vida comuns, as trocas intersubjetivas e de experiências de cuidado mútuo, além da transmissão de tradições de um indivíduo para outro (SZYMANSKI, 2002). Também são assumidas como instituições sociais, construídas a partir da dialética que se processa entre as pessoas que vivem em grupo e a estrutura social na qual estão inseridas (MIOTO, 1997).

Os marcos legais também apresentam seus entendimentos sobre entidade familiar e o Plano Nacional de Promoção, Proteção e Defesa do Direito de Crianças e Adolescentes à Convivência Familiar e Comunitária (2006), que foi aprovado com o escopo de oferecer diretrizes para a formulação e implementação de políticas públicas em prol da efetivação dos direitos de crianças e adolescentes, adota uma definição que transcende os laços de parentesco e avança na direção de considerar, na esfera simbólica e relacional, a possibilidade de outras pessoas comporem o grupo familiar.

No âmbito dos serviços sociais, em pesquisa realizada com assistentes sociais de CRAS e CREAS ${ }^{13}$ em São Paulo, pôde-se constatar que esses profissionais

\footnotetext{
${ }^{13}$ A pesquisa mencionada consta em Autora B (2010), disponível na Biblioteca do CRESS-SP. Revista Serviço Social \& Saúde. UNICAMP Campinas, v. X, n. 12, Dez. 2011
} 
identificam também como família, além dos agrupamentos formados por um dos pais e seus filhos, aqueles constituídos por pais e mães em segundas uniões conjugais, cujos filhos coabitam, formando um sistema fraterno cujos laços são afetivos e não consanguíneos. Emergiu ainda a noção de que se pode considerar família um conjunto de indivíduos que têm entre si uma história própria e laços culturais, afetivos e de proteção.

Dada a amplitude do conceito de família, existem vários enunciados possíveis, sem que isto represente confronto entre eles. Daí poder-se dizer da incompletude da definição de família e da importância de falar de algo dinâmico, em transformação. Assumindo a perspectiva de que esse primeiro espaço de acolhimento do indivíduo é múltiplo e está em constante transformação, diríamos que a família é uma unidade de convivência ${ }^{14}$, formada a partir de vínculos de parentesco, de afinidade e de reciprocidade, cuja história e percurso social ${ }^{15}$ singulares demarcam sua forma de organização interna e de intercâmbio com a sociedade naquele dado momento e lugar e, em consequência, a socialização, o cuidado e a proteção de seus membros.

Assim, considerando que a família é heterogênea e uma construção social, adentrar esse universo, por meio da intervenção profissional do Serviço Social, significa ter um olhar acurado para compreender a diversidade de suas configurações ${ }^{16}$, a qualidade das relações que ali se desenvolvem e os movimentos que traça com suas

\footnotetext{
14 Tomamos emprestado o termo "unidade de convivência" de Saraceno (2003), que usa o termo "convivência familiar" para referir-se ao conjunto de pessoas que vivem juntas.

${ }^{15}$ Por percurso social estamos considerando principalmente as experiências da família no que se refere a seu movimento em termos territoriais, culturais e de inserção no mercado de trabalho.

${ }^{16}$ A diversidade das configurações da família já está assumida socialmente, embora nem sempre devidamente compreendida, o que leva, por vezes, a certa contradição entre o discurso corrente e o "tratamento", por vezes preconceituoso, que lhe é oferecido pelos poderes públicos.
} 
redes sociais primárias, com o mercado de trabalho e o Estado. Em suma, trata-se de conhecer a dinâmica interna ${ }^{17}$ da família e dela com o meio social.

É preciso ressaltar, ainda, que lidar com famílias significa superar preconceitos, desmistificar a ideologia de família como núcleo natural e padronizado e aprofundar o conhecimento de sua realidade social, adentrando suas vicissitudes, vulnerabilidades e potencialidades.

A pesquisa que, entre outras fontes, inspirou as reflexões e posicionamentos presentes neste artigo trouxe subsídios que possibilitaram captar como os assistentes sociais veem a família na realidade da metrópole paulistana, no que se refere ao entendimento de suas fragilidades e de seus movimentos sociais pela sobrevivência, mas também de sua força e de seu saber sobre si. Identificou-se, a partir dos depoimentos obtidos, um entendimento compatível com o sustentado neste artigo, haja vista que suas manifestações, de modo geral, espraiam amplitude de compreensão e propagam os princípios do Código de Ética do Assistente Social (1993), ao reconhecer as diferenças, respeitar a diversidade e afastar preconceitos em relação à família.

Nesse sentido, a fala de uma das assistentes sociais entrevistadas nos levou a refletir sobre a ambivalência da legislação vigente ${ }^{18}$ no que se refere à concepção de família, pois ora adota um conceito amplo, incluindo a perspectiva de formação a partir de laços que transcendem o parentesco e o domicílio, ora circunscreve família a partir

\footnotetext{
${ }^{17}$ Entendemos por dinâmica familiar sua forma de organização e as estratégias por ela assumidas para garantir a sobrevivência, o cuidado e a educação de seus membros.

${ }_{18}$ Gueiros (2010) abordou a questão sobre como a família é concebida nas legislações pós-Constituição de 1988, sobretudo as relativas à justiça de infância e juventude e às políticas sociais, em comunicação para o XIII CBAS intitulada "Conceito de família nos marcos legais: aplicação na justiça de infância e juventude e nas políticas sociais”.

Revista Serviço Social \& Saúde. UNICAMP Campinas, v. X, n. 12, Dez. 2011
} 
desses dois aspectos, o que acaba por dificultar a inserção em políticas públicas demandadas $^{19}$, em especial quando se trata de família unipessoal.

Cabe ressaltar que a PNAS reconhece que "na proteção básica, o trabalho com famílias deve considerar novas referências para a compreensão dos diferentes arranjos familiares, superando o reconhecimento de um modelo único baseado na família nuclear” (PNAS, 2004, p. 29), e que “qualquer forma de atenção e/ou de intervenção no grupo familiar precisa levar em conta sua singularidade, sua vulnerabilidade no contexto social, além de seus recursos simbólicos e afetivos, bem como sua disponibilidade para se transformar e dar conta de suas atribuições” (Ibid., p. 35).

O trabalho com famílias é constitutivo da atuação do assistente social, e a PNAS propõe a esse profissional embrenhar-se no universo difuso da família, a fim de fazer desse espaço um locus de proteção social e de cidadania. Declara a PNAS que a "unidade sociofamiliar, por sua vez, permite o exame da realidade a partir das necessidades, mas também dos recursos de cada núcleo/domicílio” (PNAS, 2004, p. 15). Segundo Carloto (2006), o SUAS reconhece que as

[...] 'novas feições da família estão intrínseca e dialeticamente condicionadas às transformações societárias contemporâneas, ou seja, às transformações econômicas e sociais, de hábitos e costumes, e ao avanço da ciência e da tecnologia' [...] e tem o mérito de superar a referência de tempo e lugar para a compreensão do conceito de família (CARLOTO, 2006, p.152).

\footnotetext{
${ }^{19}$ Uma das assistentes sociais entrevistadas ilustra essa questão dizendo o seguinte: "Na hora de você contemplar um BPC, por exemplo, você pode ter lá um casal, cada parte tem o seu filho, e uma das crianças é deficiente, a outra parte são irmão afetivos, vínculo de afetividade, e legalmente eles não são considerados irmãos, né? E de que forma você vai constituir isso na construção do BPC ou para encaminhar para o Poder Judiciário?”
} 
A PNAS, que dá centralidade à família, preconiza que a matricialidade sociofamiliar deve balizar a intervenção profissional do assistente social. Mas, que entendimento temos sobre matricialidade sociofamiliar?

\section{MATRICIALIDADE SOCIOFAMILIAR: da nomeação à operacionalidade na prática profissional}

Da forma como a concebemos, matricialidade sociofamiliar é ter a família (com suas questões coletivas e singulares) como matriz de execução da Política Nacional de Assistência Social; é entendê-la como o agente motor da intervenção do assistente social. Assim, o vínculo social com as famílias é constituído a partir da

unidade familial, inter-relacionando os programas/serviços socioassistenciais e a realidade cotidiana dessas famílias e são assumidas estratégias de ação, nas quais o particular e o universal estão articulados. Em outras palavras, as famílias são o palco no qual a política de assistência social finca seus alicerces e busca, junto com esses sujeitos, engendrar possibilidades de inserção social, para garantir sua sobrevivência, o acolhimento de suas necessidades e interesses e o convívio familiar e comunitário enfim, a proteção social.

Procura-se, assim, entender o universo heterogêneo da família, situando-a em termos de classe social, de gênero e de etnia, a fim de implementar a PNAS no que se refere a matricialidade sociofamiliar. Nesse sentido, somos instigados a pensar a família a partir de seu percurso, sua inserção e seus direitos sociais e, em consequência, a formular a intervenção em bases teórico-metodológicas e técnico-operativas que assumam essa perspectiva de análise.

Esse entendimento traz novos debates para compreender a família na perspectiva da PNAS, pois ela deixa de ser sujeito fim das ações assistenciais e passa a 
ser agente principal na formulação e implementação da política pública de assistência social, com ênfase na busca pela justiça social.

A abordagem matricial da família exige que novas formas de enfrentamento das expressões da questão social sejam traçadas para e com a família, de modo integrado e articulado com os serviços socioassistenciais e as demandas que se apresentam a partir de uma interlocução que as considera sujeitos de direitos, agentes sociais, conforme defende Saraceno e Naldini (2003):

A família não é um simples terminal passivo de mudança social, mas um dos agentes sociais que contribuem para definir as formas e os sentidos da própria mudança social, ainda que com diferentes graus de liberdade e segundo as circunstâncias. (SARACENO e NALDINI, 2003, p. 21)

Entretanto, a despeito das construções teórico-metodológicas que se fundam a partir da matricialidade sociofamiliar, temos percebido que esse eixo da PNAS é pouco assumido em seu sentido estrito e com frequência tomado por centralidade da família. Talvez disso resulte, nos CRAS e CREAS de São Paulo nos quais realizamos a pesquisa já mencionada, uma operacionalização da política de assistência social que, pelo menos em termos da intervenção do assistente social, aparentemente se limita à adequação de famílias a programas, projetos e serviços existentes, os quais muitas vezes não contemplam uma leitura crítica da realidade a que estão submetidas.

Assim, pelo que pudemos depreender a partir dos resultados da investigação empírica realizada e da prática profissional em nosso universo de trabalho, implementar a matricialidade sociofamiliar na intervenção profissional nos CRAS e CREAS da cidade de São Paulo ainda constitui um grande desafio para os assistentes sociais. Verificamos que, além de o conceito requerer estudo sistemático, as políticas públicas 
continuam sendo planificadas centralmente e, deste modo, guardam pouca correlação com realidades socioterritoriais vivenciadas pelas famílias.

Nesse sentido, a fim de evitar conflito de ideias e favorecer sua aplicabilidade, entendemos que o conceito de matricialidade sociofamiliar deve ser esmiuçado, debatido, desvelado, enfim, aprofundado e divulgado, quer entre os operadores da Política Nacional de Assistência Social, quer entre seus mentores.

Nessa direção, Couto, Yazbek e Raichelis (2010) apresentam algumas questões para pensar matricialidade sociofamiliar no âmbito do SUAS, destacando o necessário rompimento com pré-conceitos relativos às diferentes configurações de famílias na população pobre e a devida proteção social para que esse grupo referencial básico possa se constituir como espaço de desenvolvimento para seus membros. Acrescentam, ainda, a importância de compreender as expressões dessa unidade de convivência advindas de suas singularidades e de seu pertencimento a uma classe social, bem como de rever as metodologias de trabalho de modo a ultrapassar o "forte caráter moralista e disciplinador que intervém nas formas de pensar a família” (COUTO, YAZBEK e RAICHELIS, 2010, p. 56).

A PNAS (2004) reconhece que relações sociais atuais podem fragilizar a capacidade funcional das famílias, comprometendo suas condições objetivas para desempenhar as funções ${ }^{20}$ que lhe são socialmente atribuídas. Essa visão exige dos representantes dos serviços públicos analisar a situação sem culpabilizar ou imputar deficiências às pessoas, mas, ao contrário, assumir que as contingências decorrentes do modo de produção capitalista sobrecarregam a família em suas atribuições, à medida

\footnotetext{
${ }^{20}$ A PNAS reconhece como funções básicas das famílias: “prover a proteção e a socialização dos seus membros; constituir-se como referências morais, de vínculos afetivos e sociais, de identidade grupal, além de ser mediadora das relações dos seus membros com outras instituições sociais e com o Estado" (2004, p. 35).
} 
que o Estado se desresponsabiliza do seu papel de regulador das relações sociais e agente promotor da cidadania.

No Brasil, o encolhimento do Estado, no que diz respeito às políticas públicas de proteção social, tem resultado na propensão de atribuir às unidades familiares a responsabilidade principal pela proteção social de seus membros. A não materialização, no cotidiano, do entendimento da questão social pode, por vezes, fomentar a tendência de impor que as demandas relativas à proteção social sejam assumidas somente na esfera privada, como se fossem uma responsabilidade individual, e não reflexos da força motriz do modo de produção capitalista.

Essa perspectiva de abordagem, que estudiosos como Mioto (2008) denominam de familismo, consiste na expectativa de as unidades familiares serem responsáveis por garantir o bem-estar de seus membros. Nesse sentido, o Estado vale-se de políticas públicas que alçam a família ao centro da discussão de forma meritocrática, valorando aquelas que conseguem prover sua manutenção, e “isso corresponde a uma menor provisão de bem-estar por parte do Estado” (ESPING-ANDERSEN, apud MIOTO, 2008, p. 135-6).

Essa é uma questão que merece ser pensada com mais profundidade, pois o “modelo” brasileiro de acolhimento, proteção e convivência dos indivíduos é culturalmente centrado na família. Contudo, isso não significa minimizar o papel do Estado na proteção social a seus cidadãos, tampouco considerar fracassados em sua tarefa social pais ou avós que não conseguem promover o cuidado e a educação de seus filhos e netos. Lembra Mioto (2008) que

[...] nos Estados de Bem-Estar de caráter familista existe uma explícita parceria entre Estado e família, e o quantum de proteção assumido pelo Estado e pela família é que caracteriza maior ou menor grau de familismo. Enquadrados nesse modelo Revista Serviço Social \& Saúde. UNICAMP Campinas, v. X, n. 12, Dez 2011 
estão países da Europa do Sul que configuram um modelo próprio de bem-estar, denominado "modelo mediterrâneo" ou "modelo católico", à medida que a ênfase institucional na regulação e na organização da proteção social recai muito mais na família que no mercado ou no Estado. Assim, ela se constitui em fonte principal de provisão das necessidades sociais. Nesse modelo, a ação pública tende a ocorrer mediante a falência na provisão de bem-estar e na sua impossibilidade de compra de bens e serviços, no mercado (Ibid., p. 136).

É sabido que, com a adoção da política neoliberal, nas últimas décadas, o Estado delegou à família a responsabilidade da proteção social, que seria do ente público. Contudo, se a economia distancia parte significativa da população da inserção no mercado formal de trabalho, as famílias desse segmento populacional não têm condições de fazer frente às vulnerabilidades sociais a que ficam expostos seus membros. A situação econômica atual forja uma família que, do ponto de vista socioeconômico, é frágil, o que torna difícil cumprir o papel protetor que lhe é imposto. Diante disso, pergunta-se: como as políticas públicas têm dado suporte às unidades de convivência para que elas alcancem autonomia na realização de seu papel social?

É indubitavelmente importante que o núcleo familiar seja valorizado no cumprimento de funções relativas à sobrevivência, ao cuidado e à socialização de crianças e adolescentes. Contudo, é necessário sopesar as pressões sociais exercidas sobre ele, considerar as vulnerabilidades presentes em seu percurso social e as contradições vivenciadas em seu cotidiano na avaliação das condições que essa família tem para, mesmo com o auxílio de políticas sociais, assumir as responsabilidades que lhe são delegadas. 
Na pesquisa empírica à qual se refere este artigo, acerca das funções da família, as assistentes sociais entrevistadas fizeram referência a alguns aspectos que, por sua importância, merecem ser mencionados. A proteção, o cuidado e o aprendizado da criança, principalmente no que se refere à sociabilidade, ao respeito pelo outro, às crenças e hábitos culturais, além dos valores morais foram enfatizados como funções da família. Foi salientado também que a família constitui o núcleo primeiro do indivíduo, no qual a aquisição da linguagem e a socialização são aspectos preponderantes. $\mathrm{O}$ intercâmbio com o meio social imediato também foi lembrado como papel da família em relação a seus membros, além da formação da identidade social.

Assim, retomamos a premissa constante na PNAS de que, para a família proteger e cuidar, ela deve ser amparada, posto que não podemos exigir algo de quem não tem condições objetivas para tanto. Cabe então ao poder público garantir suporte para que as famílias cumpram as funções que lhes são delegadas, uma vez que, com as mudanças estruturais da política econômica, os alicerces da família podem ser e em geral são abalados.

Espraiando as funções atribuídas às famílias, depreendemos que essa dimensão é campo fértil para a implementação de uma abordagem familiar embasada na matricialidade sociofamiliar, porque significa olhar para a família como sujeito de direitos e elaborar formas de enfrentamento das expressões da questão social a partir de suas realidades, com ênfase no reconhecimento de suas possibilidades e fragilidades e na contextualização socioeconômica e cultural dos conflitos que cercam o mundo familiar. Há que se ter agudeza na análise das situações e criatividade para definir novas estratégias de atenção e de elaboração do vínculo social com a família.

Do que pudemos investigar sobre o atendimento às famílias nos programas, projetos e serviços socioassistenciais, é possível dizer que as profissionais entrevistadas Revista Serviço Social \& Saúde. UNICAMP Campinas, v. X, n. 12, Dez 2011 
consideram, de maneira geral, que é necessário olhar além das demandas apresentadas pela família no primeiro momento. O entendimento das assistentes sociais em foco é que identificar as condições de trabalho, de habitabilidade, de sobrevivência, as formas organizacionais, a rede de apoio social e os hábitos culturais e de lazer da família, além das necessidades e expectativas individuais, é primordial para definir a atenção que o Estado, por meio das políticas sociais, deve oferecer à família para que ela assuma as funções que lhes são atribuídas.

Percebemos, pelos depoimentos coletados, que não são raros os casos em que a demanda apresentada é parte miúda das vulnerabilidades sociais vivenciadas pela família. Adentrar sua rotina, observando sua inserção (ou não) no mercado de trabalho, a rede de relações primárias, a rede de suporte comunitário, as interrelações de gênero e geracionais, bem como as contradições e confrontos que se estabelecem em seu cotidiano, emerge como forma de obter um entendimento mais amplo sobre essa unidade de convivência e direcionar as políticas e os serviços sociais para um atendimento mais efetivo de suas necessidades, com vistas à defesa de seus direitos e à sua imprescindível emancipação.

Por fim, podemos dizer que, do conteúdo dos depoimentos analisados, embora não tenha emergido de modo claro ou devidamente elaborado, foi possível extrair a noção de que as assistentes sociais que operacionalizam a política pública de assistência social entendem que a família está sobrecarregada frente ao atual cenário sócio-histórico e, portanto, têm dificuldade de cumprir as funções a ela socialmente definidas. Cabe indagar, contudo, se esse patamar de compreensão é suficiente para sustentar uma prática social - guardadas as devidas limitações, tendo em vista a 
flagrante desigualdade social e a ainda insuficiente implementação do SUAS ${ }^{21}$ - que contribua para a concretização de direitos e emancipação das famílias.

\section{NOTAS FINAIS}

Nossas investigações e experiências profissionais levaram-nos a considerar que o termo “matricialidade sociofamiliar” é com frequência tomado por “centralidade da família”, talvez por ser um conceito ainda insuficientemente debatido, esmiuçado.

É certo que a família é central na PNAS, haja vista que os projetos, serviços e benefícios a têm como núcleo social fundamental para a intervenção profissional, porém sua importância está além de ser ponto de convergência de políticas sociais. A família deve ser entendida em sua dinâmica cotidiana de luta pela sobrevivência e de inserção socioterritorial, considerando sua singularidade e as estratégias por ela utilizadas para proteger e cuidar de seus membros. Essa visão exige que o conceito de matricialidade sociofamiliar seja apreendido e viabilizado na execução da política de assistência social, pois somente assim haverá pertinência entre as demandas da população usuária e os programas/serviços a ela oferecidos.

Em consonância com o projeto ético-político da profissão, foi possível constatar entre os profissionais do Serviço Social, apesar das experiências dispersas em contrário, um discurso que atualmente tende a uma visão da família como construção social, calcada na perspectiva sócio-histórica, a partir da qual se entendem as pressões que o modo de produção capitalista é capaz de gerar sobre indivíduos e famílias,

\footnotetext{
${ }^{21}$ Raichelis chama a atenção para os desafios que dizem respeito à "questão do trabalho e dos trabalhadores no SUAS", destacando, em relação ao quadro de profissionais, "o universo heterogêneo de trabalhadores, composto por servidores e trabalhadores da esfera estatal nos três níveis de governo, e pela extensa 'rede' privada de entidades de assistência social, com uma diversidade de áreas de formação, acúmulo teórico-prático, vínculos e condições de trabalho” (2010, p. 761).
} 
determinando condições objetivas de vida que, muitas vezes, inviabilizam o desenvolvimento e a emancipação das pessoas e do grupo.

Parece-nos plausível supor que os assistentes sociais reconhecem que, para apreender a formação familiar, é necessário conhecer os fenômenos históricos que abarcam a sociedade e reverberam nessa referência social básica do indivíduo, dando causa a novas configurações e estratégias de sobrevivência. Admite-se igualmente que, nos espaços de implementação da política socioassistencial, a família é tomada como central nos processos profissionais de intervenção, porém percebe-se que ainda existe certa dificuldade de compreender o conceito de matricialidade sociofamiliar e operacionalizá-lo na prática cotidiana. Vislumbra-se, contudo, tendência à adoção do entendimento de que a política de assistência social busca a proteção às famílias e, para tanto, é preciso conhecê-la em profundidade, pois é em seu cotidiano que as vulnerabilidades e as potencialidades se constituem.

Assumir a perspectiva analítica a partir da qual se pensa a família como reflexo das determinações sociais que incidem sobre ela, bem como apreender e reconhecer as particularidades de seu percurso social, é inquestionavelmente importante para viabilizar a implementação da matricialidade sociofamiliar. Porém, levando em conta a ainda precária estrutura com que está sendo implementada a Política de Assistência Social, a indagação que se impõe é se é possível considerar as particularidades de cada família em termos de vulnerabilidades e potencialidades, a fim de que haja a devida articulação entre suas necessidades e seus direitos sociais, as constatações e proposições feitas a partir da intervenção profissional e a resposta estatal no que se refere à formulação e à oferta de benefícios/serviços sociais que concorram para a proteção social dessas famílias. 


\begin{abstract}
This article aims at reflecting about the sociofamiliar matriciality in conceptual terms and in its operacionality in referential spaces of social assistance, Standing in the joint between the foundations of theoretical and methodological originated from the Social Work and professional practice. Discusses the contemporary families and their questions, especially those that depend on the attention of the State to promote the care and protection to its members. In this sense, it is understood that the present situation of the socially vulnerabilized families is fruit of complex social trajectories, resulting from the social desiguality and from transformations in the labor world and in the gender relations among other aspects. From empirical data collected from social workers, enters to the analysis of aspects that guide the professional intervention in the Reference Centers of Social Assistance, and take it for guideline that an effective social protection requires the access of social rights to everyone.
\end{abstract}

KEYWORDS: Social Assistance, Family, Sociofamiliar Matriciality, Social Work

\title{
REFERÊNCIAS BIBLIOGRÁFICAS
}

BRASIL. Constituição da República Federativa do Brasil. São Paulo: RT, 2008. Lei n. 8.069, de 13 de julho de 1990. Estatuto da Criança e do Adolescente. Lei n. 12.010, de 3 de agosto de 2009. Dispõe sobre adoção e altera a Lei n. 8.069, de 13 de julho de 1990 - Estatuto da Criança e do Adolescente.

. Lei n. 12.435, de 6 de julho de 2011. Altera a Lei $n^{0}$ 8.742, de 7 de dezembro de 1993, que dispõe sobre a organização da Assistência Social.

. Ministério do Desenvolvimento Social e Combate à Fome. Secretaria Nacional de Assistência Social. Política Nacional de Assistência Social. Brasília, 2004. Secretaria Especial dos Direitos Humanos. Conselho Nacional dos Direitos da

Criança e do Adolescente. Plano Nacional de Promoção, Proteção e Defesa do Direito 
de Crianças e Adolescentes à Convivência Familiar e Comunitária. Brasília (DF):

Conanda, 2006.

. Ministério do Desenvolvimento Social e Combate à Fome. Secretaria Nacional de Assistência Social. Conselho Nacional de Assistência Social. SUAS: Sistema Único de Assistência Social. Manual Informativo para jornalistas, gestores e técnicos. Brasília, 2005.

Ministério do Desenvolvimento Social e Combate à Fome. Orientações técnicas - Centro de Referência de Assistência Social - CRAS. Brasília: MDS, 2009.

CARLOTO, C. M. Gênero, políticas públicas e centralidade na família. Revista Serviço Social \& Sociedade, n. 86. São Paulo: Cortez, 2006.

CÓDIGO DE ÉTICA PROFISSIONAL DO ASSISTENTE SOCIAL. Brasília: CFESS, 1993.

COUTO, B. R., YAZBEK, M. C. e RAICHELIS, R. A Política Nacional de Assistência Social e o SUAS: apresentando e problematizando fundamentos e conceitos. In: COUTO, B. R., YAZBEK, M. C., SILVA e SILVA, M. O. e RAICHELIS, R.(Orgs.). O Sistema Único de Assistência Social no Brasil: uma realidade em movimento. São Paulo: Cortez, 2010.

GUEIROS, D. A. Conceito de família nos marcos legais: aplicação na justiça de infância e juventude e nas políticas sociais. XIII CONGRESSO BRASILEIRO DE ASSISTENTES SOCIAIS: LUTAS SOCIAIS E EXERCÍCIO PROFISSIONAL NO CONTEXTO DA CRISE DO CAPITAL - MEDIAÇÕES E A CONSOLIDAÇÃO DO PROJETO ÉTICO-PROFISSIONAL. Anais... Brasília, jul./ago. de 2010.

MIOTO, R. C. T. Família e Serviço Social: contribuições para o debate. Revista Serviço Social \& Sociedade. São Paulo: Cortez, n. 55, nov. 1997. p. 114-30. 
Família e políticas sociais. In. Política social no capitalismo: tendências contemporâneas. São Paulo: Cortez, 2008. p. 130-48.

RAICHELIS, R. Intervenção profissional do assistente social e as condições de trabalho no SUAS. Serviço Social \& Sociedade, n. 104, São Paulo, 2010.

SANTOS, T. F. S. O trabalho com famílias nos CRAS e CREAS de São Paulo: a matricialidade sociofamiliar tem centralidade? São Paulo, 2010. Trabalho de conclusão de curso (graduação em Serviço Social). Universidade Cruzeiro do Sul.

SARACENO, C. e NALDINI, M. Sociologia da família. Lisboa: Estampa, 2003.

SARTI, C. A. Família e individualidade: um problema moderno. In: A família contemporânea em debate. 6. ed. São Paulo: Educ/Cortez, 2005.

SCHERER, C. O processo de implementação do Sistema Único de Assistência Social no município de Entre-Ijuís, RS junto à proteção integral das crianças e adolescentes. In. Revista Textos e Contextos. Porto Alegre, v. 8, n. 2, p. 274-92, jul./dez. 2009.

Disponível em http://revistaseletronicas.pucrs.br/ojs/index.php/fass/article/viewFile/6344/4643. Acesso em 21/04/2010.

SPOSATI, A. Mínimos sociais e seguridade social: uma revolução da consciência de cidadania. Serviço Social \& Sociedade, n. 55. São Paulo: Cortez, nov. 1997. p. 9-38. Horizontes da e para a política de assistência social no Brasil de 2009:

elementos para a discussão. In: Políticas públicas em debate: ciclo de seminários. São Paulo: Fundap, 2009. p. 1-19. Disponível em http://www.fundap.sp.gov.br/debatesfundap/pdf/nono_seminario/ExposiCACAodeAlda izaSposati.pdf. Acesso em 10/05/2010 
SZYMANSKI, H. Viver em família como experiência de cuidado mútuo: desafios de um mundo em mudança. Revista Serviço Social e Sociedade, n. 71. São Paulo: Cortez, set. 2002. p. 9-25. 